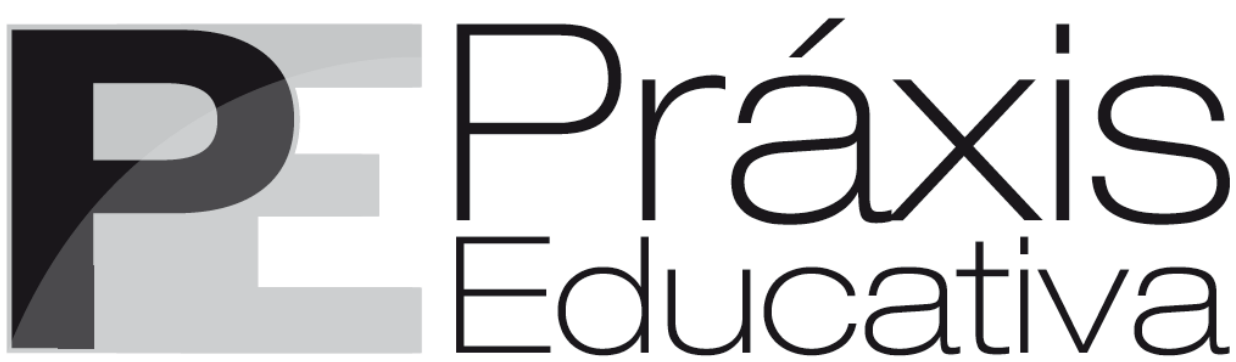

ISSN 1809-4309 (Versão online) DOI: 10.5212/PraxEduc.v.12i3.014

\title{
Professor temporário: um passageiro permanente na Educação Básica
} brasileira

\section{Temporary teacher: a permanent passenger in Brazilian Basic Education}

\section{Profesor temporario: un pasajero permanente en la Educación Básica \\ brasileña}

\author{
Allan Kenji Seki* \\ Artur Gomes de Souza ${ }^{* *}$ \\ Filipe Anselmo Gomes ${ }^{* * *}$ \\ Olinda Evangelista***
}

Resumo: Neste artigo, procuramos explorar os dados sobre os professores temporários no Censo Escolar da Educação Básica (2011-2015). A contratação dos professores revela uma das faces da precarização do trabalho docente no Brasil, cuja perversidade atinge a vida de quase um milhão dos professores temporários que atuam na Educação Básica. É o retrato de uma tragédia cotidiana, $41 \%$ dos professores trabalham sem ter a certeza da continuidade de suas atividades, privados da possibilidade de planejar em longo prazo suas relações didático-pedagógicas, alheados da escolha de recursos e materiais ou, mesmo, de planejamento. São professores que precisam descobrir, a cada fim de contrato, como irão continuar ganhando a vida, enquanto são eles os responsáveis - e responsabilizados - pela educação de 48,8 milhões de estudantes. A tragédia não é nova ou passageira, mas característica da estrutura educacional brasileira.

Palavras-chave: Professores temporários. Educação Básica. Trabalho docente.

Abstract: In this paper, we try to explore data on temporary teachers in the Basic Education School Census (2011-2015). The hiring of teachers reveals one of the faces of the precariousness of teaching work in Brazil, whose perversity affects the lives of almost one million temporary teachers who work in Basic Education. It is the portrait of a daily tragedy, $41 \%$ of teachers work without being sure of the continuity of their activities, deprived of the possibility of planning in the long term their didacticpedagogical relations, oblivious of the choice of resources and materials or even planning . They are teachers who need to discover, at each end of the contract, how they will continue to make a living, while

\footnotetext{
* Doutorando em Educação pela Universidade Federal de Santa Catarina (UFSC). E-mail: <allanknj@gmail.com>.

** Mestrando em Educação pela Universidade Federal de Santa Catarina (UFSC). E-mail: $<$ artur.gsouza@hotmail.com>.

*** Auxiliar de cátedra na Universidad Nacional de la Patagonia San Juan Bosco (UNPSJB), Argentina. E-mail: $<$ filipeanselmogomes@gmail.com>.

**** Professora da Universidade Federal de Santa Catarina (UFSC). E-mail: <olindaevangelista35@hotmail.com>.
} 
they are responsible - and held accountable - for the education of 48.8 million students. The tragedy is not new or fleeting, but characteristic of the Brazilian educational structure.

Keywords: Temporary teachers. Basic Education. Teaching work.

Resumen: En este trabajo, se buscó explorar los datos sobre los profesores temporarios en el Censo Escolar de la Educación Básica (2011-2015). La contratación de los profesores revela una de las caras de la precarización del trabajo docente en Brasil, cuya perversidad alcanza la vida de casi un millón de los profesores temporarios que actúan en la Educación Básica. Es el retrato de una tragedia cotidiana, el 41\% de los profesores trabaja sin tener la seguridad de la continuidad de sus actividades, privados de la posibilidad de planear a largo plazo sus relaciones didáctico-pedagógicas, alejados de la elección de recursos y materiales o, incluso, la planificación. Son profesores que necesitan descubrir, a cada fin de contrato, cómo van a seguir ganándose la vida, mientras son ellos los responsables -y responsabilizadospor la educación de 48,8 millones de estudiantes. La tragedia no es nueva o pasajera, sino característica de la estructura educativa brasileña.

Palabras clave: Profesores temporarios. Educación Básica. Trabajo docente.

\section{Introdução}

"Seja um professor. Poucos têm nas mãos o poder de mudar um país." (BRASIL, 2017a). Entre os jargões usados contra o professor, um dos mais truculentos é esse, do Ministério da Educação. A crueldade contra o professor, no Brasil, vem sendo exercida em larga escala e sem pejo. Enjaulado nos slogans do "empoderamento", do "empreendedorismo", da "responsabilização", sintetizados na "capacidade de mudar o mundo" - pedras de toque nas políticas docentes em andamento -, o professor subsiste em condições profundamente adversas. Tal situação, entretanto, tem sido alimentada pelo Governo Federal, seja o petista, seja o peemedebista do ilegítimo Temer.

Na página do MEC, “Seja um professor", afirma-se que, em 2009, para ensinar os então 52 milhões de alunos da Educação Básica, existiam 1,8 milhão de professores, dos quais 1,5 atuavam apenas nas escolas públicas (BRASIL, 2017b). Informa-se ainda que, em 2007, 63,8\%

\footnotetext{
${ }^{1}$ Carvalho (2014, p. 181) examina o tema do "empoderamento", indicando que, quer como conceito, termo ou estratégia de intervenção, cumpre, pelo menos, quatro funções tendo em vista produzir: 1) o “'desclassamento” da classe trabalhadora"; 2) a "mistificação ideológica"; 3) o "apassivamento da classe trabalhadora e suas organizações" e 4) a "desresponsabilização do Estado e desoneração do capital".

${ }^{2}$ Coan (2011, p. 211), ao discutir a educação para o empreendedorismo, assinala que: "Os apelos às pessoas para que empreendam é muito forte, em diversos setores da sociedade [...] e se encontra bem sedimentado no ambiente escolar; [...] se delineia na atualidade um novo perfil de professor - o do 'professor empreendedor"'. O conceito de empreendedorismo é entendido como um dos elementos que operam sobre o sentido do trabalho na atualidade, cujo aspecto gelatinoso e polissêmico contribui para o consentimento passivo de trabalhadores a uma miríade de formas de vinculação ao emprego. Tais formas alcançam e combinam desde os contratos formais até os extremos de informalidade. O empreendedorismo diz respeito ao campo da produção das vontades coletivas, o qual responsabiliza o trabalhador individualmente por suas capacidades criativas e inventivas para produzir formas de se disponibilizar ao mercado de maneira profundamente marcada por certo "voluntarismo". Ou seja, vender sua força de trabalho urgentemente e sob qualquer forma e responsabilizar-se individualmente pelo seu fracasso.

3 Evangelista (2017, p. 168, grifos da autora) afirma que: "Embora o slogan responsabilização docente aposte no 'empoderamento' docente, o que esconde, justamente, é um profundo processo de fazer o professor arcar com consequências escolares, econômicas, sociais que não são de sua alçada. Já referimos o cínico deslocamento conceitual operado, pelo qual explica-se problemas sociais e econômicos como derivados do campo educacional - e não da materialidade econômica. [...]. Se os problemas socioeconômicos nascem no campo da educação, se nele devem encontrar a solução, se o professor - embora responsabilizado - não tem competência para tal solução, temos aqui um falso dilema, consequência do movimento ideológico burguês dominante. Sendo o Brasil a sexta economia do mundo, concluímos que não está em questão a qualidade docente propriamente, mas o seu uso para construir uma explicação palatável que justifique o desemprego estrutural e as relações de exploração em que se encontra a classe trabalhadora - fonte de risco para os interesses capitalistas".
}

Práxis Educativa, Ponta Grossa, v. 12, n. 3, p. 942-959, set./dez. 2017 Disponível em: <http://www.revistas2.uepg.br/index.php/praxiseducativa> 
dos professores trabalhavam em turno único e $83 \%$ em escolas urbanas. Embora os números possam ser corretos, a forma como são utilizados politicamente está clara e intencionalmente edulcorada, como soe acontecer com discursos que têm em vista construir consensos gerais em torno de interesses particulares. Para derrubar a suposta cegueira governamental, recorremos às informações produzidas por um de seus órgãos, o Instituto Nacional de Estudos e Pesquisas Educacionais Anísio Teixeira (INEP), particularmente no que tange às formas contratuais às quais são submetidos os professores, no período de 2011 a 2015.

Esclarecemos que, neste texto, não discutiremos as ignóbeis situações vividas pelo professor temporário nas escolas, ou em outros espaços, nem as variadas formas de contratação temporária desenvolvidas no país que redundam em direitos desiguais para trabalhadores com a mesma função e formação. Salientamos, ademais, que consideramos os celetistas e concursados como estáveis ${ }^{4}$. Embora o primeiro seja passível de demissão, porta direitos assemelhados aos concursados, em geral negados aos contratados em caráter temporário. De mais a mais, entendemos que o epíteto "precarizado" não pode ser usado como sinônimo de temporário, posto que esse fenômeno abrange muitos aspectos. Marin (2010) assinala que a precarização do trabalho docente liga-se à precarização do trabalho decorrente da expansão do neoliberalismo, pós-1990, no Brasil, e aparece na área educacional a partir de 2002. A autora refere-se a "[...] mudanças marcadas por características com conotações negativas no conjunto do exercício da função docente" (MARIN, 2010, n.p.), as quais dividiu em dois blocos. O primeiro, "significados caracterizadores", engloba

[...] flexibilização; intensificação; desemprego; desprofissionalização; degradação; sobrecarga; cobranças; fragilização; desvalorização; competitividade; condições de trabalho e de pesquisa; perda de autonomia; novas categorias de trabalhadores, sobretudo os temporários; ausência de apoio à qualificação; e, ainda, algumas especificações da esfera tais como valorização do saber da experiência em detrimento do pedagógico; ação docente pouco sólida em termos de conhecimento; envolvimento dos professores em trabalhos burocráticos. (MARIN, 2010, n.p.).

O segundo, "consequências de sua existência", reúne

[...] desgaste; cansaço excessivo; sofrimento; desistência; resistência; adoecimento; isolamento; sentimentos e conflitos nas relações com alunos, pares e gestores; desorganização dos trabalhadores; perda de controle sobre o próprio trabalho; constrangimentos. (MARIN, 2010, n.p.).

O endeusamento do professor, partilhado por governos, Organizações Multilaterais $(\mathrm{OM})$, intelectuais e aparelhos ditos privados de hegemonia, tem em vista criar a ilusão de que por considerá-lo fundamental - provê-se a ele todas as condições de formação e trabalho. Essa abstração pretende obliterar uma importância que carece de objetividade, tal como expressou Marin (2010) acerca da precarização do trabalho docente. A presumida importância docente vem cercada de inúmeras formas de desqualificação, seguidas de projetos reformistas. Pode-se ver isso no documento Dimensiones del éxito en educación (BID, 2014), no qual o Banco Interamericano de Desenvolvimento indica que o grande desafio é alcançar o "êxito" educacional. Segundo a agência, o professor juega un rol muy importante en el aprendizaje estudiantil; disso deriva propostas de

\footnotetext{
${ }^{4}$ Miranda (2006, p. 6, grifos da autora) diverge dessa classificação por entender que existem "[...] três formas predominantes de contratação na rede pública: o professor efetivo, o professor temporário e o professor precarizado. $\mathrm{O}$ professor efetivo é o servidor público, concursado, estável, estatutário; já o professor temporário é aquele profissional com contrato por tempo determinado, em substituição ao incompleto quadro efetivo, organizado sob o regime da CLT; e, por fim, o professor precarizado que é aquele que realiza a ampliação de carga horária via contrato provisório - pode ser servidor efetivo ou temporário da rede de ensino - sem nenhum direito trabalhista como licença médica, férias, $13^{\circ}$ salário, na maioria dos casos". Além desses, a autora refere as terceirizações extrajurídicas, cujos contratos derivam de formas acordadas nas escolas.
}

Práxis Educativa, Ponta Grossa, v. 12, n. 3, p. 942-959, set./dez. 2017 Disponível em: <http://www.revistas2.uepg.br/index.php/praxiseducativa> 
reformas na carreira e na formação para atraer, desarrollar, motivar y retener a los mejores profesionales en la carrera docente (BID, 2014). Também o Banco Mundial entrou na disputa pela melhoria da "qualidade da educação". O documento What matters most in teacher policies (WORLD BANK, 2012) propõe diretrizes para resolver o problema das "oportunidades de aprendizagem", entre elas, o rompimento da estabilidade laboral. Professores com menor estabilidade seriam menos resistentes às mudanças e mais propícios a desenvolver um bom trabalho se remunerados por desempenho dos alunos em avaliações de larga escola ${ }^{5}$.

A "sacralização" da Educação, associada à inclusão social, à redução da pobreza e ao aumento da equidade, não resiste, todavia, ao teste das evidências. Sob o discurso humanitário, subjaz o dado concreto: em 2016, 55,1\% dos municípios não pagou sequer o piso salarial nacional, à época $R \$ 2.135,64 ; 61,6 \%$ não cumpriram a jornada de $1 / 3$ da carga horária prevista para planejamento de aulas (CNTE, 2017); oito estados da federação não cumpriram ambas as normas (CNTE, 2016). Em 2015, os temporários atenderam 34\% das turmas das redes de Educação Básica pública, federal, estaduais e municipais, ferindo a legislação que prevê um máximo de 10\% de temporários (BRASIL, 2014a). Muitos desavisados imaginam que os professores merecem essa situação em razão de suas supostas deficiências; outros afirmam, com intencionalidade política indubitável, que seria necessário retirar-lhes os "privilégios".

Os problemas dramáticos enfrentados pelo professor resultam de processos intensivos de precarização de seu trabalho. Uma parte importante desse movimento histórico de degradação da atividade docente é a existência do professor temporário ${ }^{7}$. Compõem sua tragédia o pequeno ou excessivo número de aulas; salários baixos e mesmo menores que os dos efetivos ${ }^{8}$; aulas em várias escolas; disciplinas diferentes para o mesmo professor; conjugação de trabalho efetivo e temporário; outros trabalhos para complementar a renda, entre múltiplos desdobramentos pedagógicos e políticos. Refira-se ainda que a demanda legal de universalização da Educação Préescolar teve desdobramentos importantes, posto que, em 2015, estava sendo feita praticamente com professores temporários municipais.

De nosso ponto de vista, as formas de contratação que imperam nas redes públicas de ensino permitem apreender algumas das contradições e ilusões que formatam as políticas docentes. Neste artigo, discutiremos um dos aspectos mais candentes, qual seja, o que diz respeito aos professores temporários. Nossa análise privilegia, então, as informações sobre o professor temporário nos microdados do Censo Escolar publicado pelo INEP para o período 2011-2015, abrange o território nacional e procura detalhar em que situações há maior incidência desse profissional.

\footnotetext{
${ }^{5}$ Decker (2015, p. 44), ao analisar o documento Professores Excelentes. Como melhorar a aprendizagem dos estudantes na América Latina e no Caribe (WORLD BANK, 2014), compreende que o Banco reitera a falaciosa funcionalidade docente para o crescimento econômico como resultado de uma "[...] pesquisa [que] investigou práticas docentes na sala de aula - com observações de mais de 15.000 professores em sete países da América Latina e do Caribe”. Tal pesquisa identificou "[...] três áreas principais de reforma política, a saber: recrutamento, capacitação e motivação de professores” (DECKER, 2015, p. 44).

${ }^{6}$ O inciso II do artigo 37 da Constituição Federal de 1988 prevê concurso público para contratação pela esfera pública; entretanto, o inciso IX permite contratações de outro tipo, desde que necessária, de interesse público e temporária, limitada a dois anos (BRASIL, 1988).

${ }^{7}$ Professores temporários são uma realidade na história da educação brasileira; entretanto, não temos informações precisas suficientes para traçar um quadro mais completo, haja vista que a variável sobre as formas de contratação docente começou a ser coletada (pelo Censo Escolar do INEP) a partir de 2011.

${ }^{8}$ Um exemplo é o caso paranaense em que os temporários recebem 40\% menos que os estáveis para a mesma carga horária (GODOY, 2014).
}

Práxis Educativa, Ponta Grossa, v. 12, n. 3, p. 942-959, set./dez. 2017 Disponível em: <http://www.revistas2.uepg.br/index.php/praxiseducativa> 


\section{Apontamentos metodológicos}

Em 2015, na rede pública, existiam 2.069.893 de professores registrados nas tabelas "Docente" do Censo Escolar da Educação Básica realizado pelo INEP; se considerados os vínculos dos docentes às turmas da Educação Básica, chegamos a 9.426.781 de casos. Foi sobre o último número que trabalhamos para compreender o comportamento das formas de contratação, considerando todos os casos, os quais foram transformados em "percentual de docentes com contratos temporários". A base para o cálculo do índice proposto segue a equação:

\section{Percentual de Docentes com contratos temporários}

$$
=\left(1-\frac{\text { Efetivos }+ \text { Celetistas }}{\text { Total de Contratos }}\right)
$$

O indicador proposto permitiu verificar o grau de vulnerabilidade das relações de trabalho do professor, segundo o critério da efemeridade do tipo de contrato, ou seja, levantamos os dados que denunciam a gravidade da sua vulnerabilidade, tendo em vista suas repercussões políticas e pedagógicas. O indicador relaciona o percentual de professores do G2 (contratos temporários, terceirizados e sem vínculo), o total de contratos e os contratos do G1 (celetistas e efetivos).

Ressaltamos que o INEP inseriu nas tabelas "Docente" quatro nomenclaturas para identificar formas de contratação: concursado, efetivo ou estável (1), contrato temporário (2), contrato terceirizado (3), contrato CLT (4) (a partir de 2012). Levando em conta essa classificação, dividimos os vínculos docentes em dois grupos: Grupo 1 (G1), no qual agregamos concursados e celetistas ${ }^{10}$; Grupo 2 (G2), temporários, terceirizados e sem preenchimento (por nós interpretado como sem vínculo trabalhista ou voluntário), este discutiremos mais profundamente.

\section{Onde estão os temporários?}

A primeira constatação importante é a de que, entre 2011 e 2015, houve um aumento do número absoluto de professores da Educação Básica no setor público, escancarando-se o fato de que os professores temporários saltaram de $37 \%$ para $41 \%$, quase um milhão de professores! Nesse segmento, os voluntários foram os que mais cresceram, 17,37\% de 2011 para 2015.

Os municípios, em 2015, apresentavam maior percentual de turmas atendidas por trabalhador temporário, 36\% frente a 32\% nas Redes Estaduais. A ausência de uma relação orgânica entre as várias esferas federadas e o descaso com a escola pública fazem com que o percentual de professores com contratos temporários seja maior em escolas de zona rural nas três esferas administrativas. Nas redes estaduais, em 2015, o percentual de temporários era de $47 \%$ na zona rural e $31 \%$ na urbana; nas redes municipais metade dos professores da zona rural tinham contratos temporários em contraposição aos $33 \%$ da zona urbana.

De modo geral, dos 5.570 municípios, apenas 661 (11,8\%) apresentaram 10\% ou menos de contratos temporários, em 2015; 1.711 acumularam 50\% ou mais de contratos temporários.

\footnotetext{
9 Para a manipulação dos microdados, utilizamos programas com código livre, o programa $R$ (R CORE TEAM, 2016) e o pacote ffbase (JONGE; WIJFFELS; VAN DER LAAN, 2016).

10 Celetistas são professores contratados pela Consolidação das Leis do Trabalho (CLT). Contudo, as reformas trabalhista e da previdência, se ocorrerem, alterarão substantivamente a CLT. Também a flexibilização trabalhista afetará as formas de contrato de professores.
}

Práxis Educativa, Ponta Grossa, v. 12, n. 3, p. 942-959, set./dez. 2017 Disponível em: <http://www.revistas2.uepg.br/index.php/praxiseducativa> 
Entre os que têm maior percentual, Paripueira (AL) destacou-se com 92\%. Apenas oito municípios, em 2015, não tinham docente temporário ${ }^{11}$ e seis atingiram $100 \%$ de temporários ${ }^{12}$.

O percentual de professores temporários, cruzado como número de turmas por Estado, contabiliza as redes municipais, estadual e federal. Entre os estados com maior percentual de temporários, o primeiro lugar coube ao Mato Grosso do Sul, que variou de 55\% para 61\% entre 2011 e 2015. Espírito Santo e Alagoas chegaram a 2015 com 60\% de trabalhadores temporários. Entre os menores percentuais, estão Rondônia (18\%), Sergipe (16\%), São Paulo (16\%) e Rio de Janeiro (15\%). Em 17 estados, o índice aumentou.

Em se tratando apenas da rede estadual pública, Alagoas contou com o maior percentual, 83\% no ano de 2015. O Espírito Santo ocupou a segunda posição, 64\%, em 2011, para 71\%, em 2015. O Piauí, no mesmo período, pulou de $42 \%$ para 63\%. O Mato Grosso do Sul, na quarta posição, manteve estável o percentual de temporários, de $58 \%$, em 2011, passou para $60 \%$ em 2015. Minas Gerais, no quinto lugar, teve variações no período analisado, de 25\%, em 2011, para $11 \%$, em 2013, e 55\%, em 2015 $5^{13}$. Rio de Janeiro (3\%), Sergipe (3\%), Pará (12\%) e São Paulo $(13 \%)$ são os estados com os menores percentuais de temporários em 2015.

No que toca às capitais, e somadas as distintas redes públicas de ensino, percebemos que, em 2015, a variação no percentual de contratação temporária é gritante: Maceió possuía 63\% enquanto Rio de Janeiro e São Paulo contabilizavam 9\% de temporários ${ }^{14}$.

\section{Formação, jovens e temporários}

O crescimento de temporários nas redes públicas de ensino não se deve à ausência de formação, visto que, em 2015, 70,9\% cumpriram a exigência da Lei de Diretrizes e Bases da Educação Nacional (LDBEN), de 1996 (BRASIL, 1996), isto é, tinham o Curso Normal em nível médio $(7,9 \%)$ ou curso superior (63\%). Do total de $41 \%$ de temporários, no Brasil, 21,5\% tinham especialização, $0,8 \%$ Mestrado e $0,1 \%$ Doutorado. Esses dados indicam que há uma juventude formada, porém com emprego instável. Havia também uma concentração de temporários nos anos finais do Ensino Fundamental, 28\%, e no Ensino Médio, 23\%, períodos em que há maior evasão discente. Esclarece-se o desdém quanto à escolarização juvenil, posto que a rotatividade de docentes e as distorções relativas às disciplinas - como o caso de professores que atuam em disciplinas distintas de seu campo de formação - colaboram para o processo de evasão.

O Tribunal de Contas da União, em relatório sobre o Ensino Médio no Brasil, constatou, com base nos dados do Censo Escolar de 2012, que "[...] onze estados apresentaram índices de contratação de professores temporários na faixa entre $40 \%$ e $67 \%$ ", algo que "[...] cria verdadeiras subcategorias de professores, sem a mesma remuneração e sem outros direitos viabilizados por meio de vínculo minimamente estável com os governos estaduais” (BRASIL, 2014b, p. 24-25).

\footnotetext{
${ }^{11}$ São eles: Passagem, Rui Barbosa, Itajá e Japí (RN), Santa Maria Madalena (RJ), São Francisco (SE), Pederneiras (SP) e Guaíba (RS).

12 São eles: Alto Alegre (RR), Vazante (MG), Matipó (MG), Santa Fé de Minas (MG), Alto Rio Doce (MG) e Pinto Bandeira (RS).

13 A variação nesse percentual relaciona-se à decisão de procedência da Ação Direta de Inconstitucionalidade 4876, que julgou inconstitucional a lei estadual que tornava efetivos os trabalhadores que estavam há cinco anos ou mais como temporários. Segundo o julgamento, “[...] a lei promoveu a investidura de profissionais da área de educação em cargos públicos efetivos sem a realização de concurso público” (STF, 2014).

${ }^{14}$ Florianópolis, capital de Santa Catarina, contava com 39\% e o estado com 47\% de temporários.
} 
Vê-se que naqueles pontos da trajetória escolar em que seria necessária maior atenção às condições de trabalho e ensino há uma concentração de professores temporários. Essa negligência com o jovem professor repercute no jovem aluno que não conclui seu percurso escolar básico e não pode aceder à Educação Superior. Certamente esse não é o único fator determinante da evasão, pois o jovem trabalhador muitas vezes deixa a escola por demandas de sua existência e pressionado por situações que escapam à organização escolar e à sua expectativa vital. Nem é preciso lembrar que dos $18,1 \%$ de jovens de 18 a 24 anos que chegam ao nível superior (OBPNE, 2017), em torno de apenas 20\% entrarão nas universidades públicas ${ }^{15}$. Os demais irão para o ensino privado, majoritariamente particular, e cairão nas malhas dos financiamentos que, hoje, ineditamente, endivida parte substancial dessa juventude ${ }^{16}$.

O jovem aspirante a professor não tem saída, pois o mercado de trabalho docente e suas possibilidades de inserção estão vinculados organicamente à escolarização, bem como às formas temporárias de contrato. Os maiores percentuais de trabalhadores temporários concentram-se nas faixas de escolaridade "fundamental incompleto" (95\%) e "fundamental completo" (96\%), percentuais considerados dentro do total da própria faixa, pequenos em número absoluto, mas incompreensível que ainda existam. Somando-se a eles, o "Ensino Médio-Normal/Magistério", entre 2011 e 2015, houve aumento generalizado dos temporários. Nas faixas de escolaridade "ensino superior completo" e "especialização", o percentual manteve-se com pequena variação. Entre aqueles com "Mestrado" e "Doutorado", uma pequena redução percentual foi observada: de $16 \%$ para $13 \%$ e $14 \%$ para $12 \%$, respectivamente ${ }^{17}$. Conclui-se que as formas temporárias de contrato atingem os professores menos escolarizados. Disso decorre que as fases iniciais da escolarização também se veem em situação difícil, dado seu alto percentual de temporários.

Por um lado, os alunos da rede pública sofrem os efeitos do trabalho intermitente; por outro, os jovens professores enfrentam problemas sérios não apenas para encontrar emprego, como encontrar empregos condizentes com sua formação e exigências vitais mínimas. Uma larga faixa da juventude brasileira submete-se às condições precárias do trabalho docente, que começam no contrato e continuam dentro da escola.

\section{Os temporários voluntários}

Tanto o Ensino Médio quanto o Ensino Fundamental foram afetados pelas políticas de Educação Integral, o que importou em excesso de temporários nesses níveis. No caso do Ensino Médio Inovador (BRASIL, 2016a), proliferou o trabalho temporário; no Fundamental, o Programa Mais Educação (BRASIL, 2013a) ${ }^{18}$ cresceu com o temporário, particularmente por

\footnotetext{
${ }_{15}$ Segundo o Observatório do PNE, em 2014, somente 5,5\% das novas matrículas na Educação Superior foram na rede pública (OBPNE, 2017).

16 Em matéria de 2012, Prado (2012) assinala que, no Brasil, “[...] 54\% dos desempregados [eram] jovens entre 18 e 29 anos". A ampliação do crédito estudantil, com o Fundo de Financiamento Estudantil (FIES), tinha crescido "[...] 1.150\%, 500 mil estudantes utilizam o fundo, o que equivale a R\$1,6 bilhão. Só em 2012 foram 140 mil novos contratos". O resultado dessa política foi o endividamento de parcela importante dos jovens. "Atualmente, $82 \%$ das matrículas no ensino superior são feitas em universidades privadas, sendo que cinco delas são as maiores do país." Cresceu a dívida e com ela a inadimplência. Segundo o Sindicado das Mantenedoras de Ensino Superior (Semesp), “[...] a taxa de inadimplência considerando mensalidades atrasadas por mais de 90 dias, atingiu 8,83\% em 2015 - o valor mais alto desde 2010" (G1, 2016).

${ }^{17}$ Os professores temporários são, em média, mais novos (34,9 anos) que os efetivos (42,3 anos).

18 A Resolução N 34, de 6 de setembro de 2013 (BRASIL, 2013b, grifos nossos): "Destina recursos financeiros, nos moldes operacionais e regulamentares do Programa Dinheiro Direto na Escola (PDDE), a escolas públicas municipais, estaduais e do Distrito Federal, para assegurar que essas realizem atividades de educação integral e funcionem nos finais de semana, em conformidade com o Programa Mais Educação. [...] Art. $5^{\circ}$ Além dos recursos
}

Práxis Educativa, Ponta Grossa, v. 12, n. 3, p. 942-959, set./dez. 2017 Disponível em: <http://www.revistas2.uepg.br/index.php/praxiseducativa> 
meio da lógica do trabalho voluntário. Aqui o INEP operou uma prestidigitação: a educação integral depende do voluntário que, entretanto, não aparece como professor nas tabelas "Docente". A nomenclatura "voluntário", cujo contrato ocorre pela Lei do Voluntariado ${ }^{19}$, criou um novo tipo docente, não reconhecido como professor e, portanto, não merecedor do piso salarial; seus vencimentos vêm sob a forma de "ressarcimento" ou bolsa. Seu cadastro aparece com a nomenclatura "profissional/monitor de atividade complementar"; contudo, no banco "Alunos" este "não docente" será considerado "docente". Ou seja, as atividades que desenvolver com alunos serão consideradas "educação integral" ou "ensino médio inovador". Em ambos, o percentual de temporários atinge $81 \%$. Embora fundamental para a consecução desses programas, o professor é obrigado a assinar um contrato de voluntário - não professor mediante o qual abre mão, no presente ou no futuro, de qualquer tipo de reconhecimento de seus direitos trabalhistas.

A mágica da troca de nome - de professor para "profissional/monitor de atividade complementar" - redundou em uma pequena diminuição de professores estritamente temporários, perceptível nos dados do INEP de 2016, comemorado pelo Governo Federal. Os professores em situação efêmera, todavia, não desapareceram!

A fragilidade desses vínculos do docente e da própria política de educação integral nacional no período analisado pode ser verificada no recente relatório do INEP em que se vê a pouca seriedade do Governo na condução dessa parcela educacional: "[...] as matrículas em tempo integral do ensino fundamental caíram 46\% em 2016 e o percentual de alunos em tempo integral passou de 16,7\% em 2015 para 9,1\% em 2016” (BRASIL, 2017c) ${ }^{20}$.

\section{Mais absurdos}

Outros dados afetam a Educação Básica: as categorias "Auxiliar ou Assistente educacional, Monitor de atividade complementar e intérprete de libras", contratados para um trabalho claramente pedagógico - mas não docente (sic!) - como auxiliares de turma, voluntários no Ensino Médio Inovador e no Mais Educação, intérprete de Libras, respectivamente, chegaram em 2015 com 100\% de contratos temporários! Tal absurdo vem acompanhado de outros: a disciplina de Língua Indígena conta com 81\% de temporários; Libras, com 57\%; e Outras Línguas, com $48 \%{ }^{21}$. A presença dessas disciplinas e desses programas na escolarização deriva de políticas focais recentemente incorporadas na legislação, especialmente sob o signo da inclusão.

de que trata o art. $4^{\circ}$, serão destinados recursos de custeio às escolas que optarem pela oferta de atividades nos finais de semana, em conformidade com a ação específica Relação Escola-Comunidade, indicada no correspondente Plano de Atendimento da Escola, devendo tais recursos ser empregados: [...] III - no ressarcimento das despesas com transporte e alimentação dos voluntários responsáveis pelo acompanhamento das atividades do programa, no valor de $R \$ 60,00$ (sessenta reais) mensais, por escola acompanhada, podendo atender, no máximo, 5 (cinco) escolas. [...] $\int 6^{\circ} \mathrm{O}$ ressarcimento das despesas especificadas nos incisos II e III deste artigo será efetivado mediante apresentação de Relatório e Recibo Mensal de Atividades Desenvolvidas por Voluntário, o qual deverá ser mantido em arquivo pelo prazo e para os fins previstos nas normas do PDDE vigentes".

19 A Lei do Voluntariado, no 9.608, de 18 de fevereiro de 1998, com cinco artigos, é clara. O Art. 10 reza que: "Considera-se serviço voluntário, para os fins desta Lei, a atividade não remunerada prestada por pessoa física à entidade pública de qualquer natureza ou a instituição privada de fins não lucrativos que tenha objetivos cívicos, culturais, educacionais, científicos, recreativos ou de assistência à pessoa. Parágrafo único. O serviço voluntário não gera vínculo empregatício, nem obrigação de natureza trabalhista previdenciária ou afim.” (BRASIL, 1998, p. 2).

20 A remodelação do Programa Mais Educação ocorreu em 2016, proposta pelo então Ministro da Educação, Aloizio Mercadante, e realizada pelo atual, Mendonça Filho (TOKARNIA, 2017).

21 A disciplina "informática ou computação" tem poucos temporários, mas é necessário considerar sua pequena introdução na escola e um quadro de professores bastante restrito.

Práxis Educativa, Ponta Grossa, v. 12, n. 3, p. 942-959, set./dez. 2017 Disponível em: <http://www.revistas2.uepg.br/index.php/praxiseducativa> 
Contudo, se no discurso político a inclusão figura como central - abrangendo amplo escopo de "diversidades" -, objetivamente o discurso do Estado não se realiza - e não era para se realizar -, deixando-se abandonados os mesmos setores ressaltados como necessitados de tais políticas. Coincidindo com as demandas do capital, Matemática concentra apenas 10,1\% dos temporários e Língua Portuguesa 9,7\%.

Interessante considerar, também, que, em 2015, 25,64\% dos professores não declararam sua cor. Dos temporários que declararam, os brancos $(59,56 \%)$ representam, ao mesmo tempo, a maioria na profissão docente e com contratos mais estáveis, $29 \%$. Na contramão estão os pardos ou pretos, com 39,14\% do professores, dos quais 43\% são temporários. Os amarelos (0,78\%) e indígenas $(0,53 \%)$ são minoria, porém entre os primeiros o percentual de temporários é menor, $22 \%$, enquanto entre os indígenas chega a $71 \%$. Em relação ao sexo, $69,1 \%$ são temporárias e $30,9 \%$ temporários. No G1, dos professores estáveis, há maior percentual de professoras, 69,8\%, que professores, $30,9 \%$.

Agregue-se que o Ensino a Distância $(\mathrm{EaD})$, em geral vinculado à Educação de Jovens e Adultos (EJA), tem um percentual elevado de temporários: $67 \%$ na categoria "Docente titular EAD" e 84\% na "Docente tutor EAD". Confirma-se, pois, que os contratos temporários alcançam as áreas da educação mais débeis. O mesmo ocorre com os auxiliares, assistentes, monitores e intérpretes de Libras. Não é o caso de discutirmos aqui, mas vale ressaltar o tratamento dado aos voluntários do Ensino Médio Inovador e Mais Educação em relação aos tutores da EaD. Os primeiros, embora possuam tarefas pedagógicas não são considerados docentes; os tutores, ao contrário, são assim registrados.

De outro lado, nosso argumento do abandono intencional das redes públicas fortalece-se ao constatarmos que, no que tange aos tipos de unidades educacionais, em 2015, houve grande crescimento de temporários nas "classes hospitalares", "unidades de atendimento socioeducativo" e "unidades prisionais". Nos dois últimos, permaneceram as proporções mais elevadas de temporários, $68 \%$ e $89 \%$. Reiteram-se as determinações de classe no acesso à escolarização de sujeitos privados de liberdade, seja crianças e adolescentes, nas unidades socioeducativas, seja na EJA, nas unidades prisionais. Engrossa o caldo o excesso de temporários na Educação Infantil, 44\%, e no Ensino Profissional, 36\%. No Ensino Fundamental e Médio regular o percentual de temporários fica abaixo de $30 \%$.

Há diferentes explicações nos manuais de preenchimento do Censo Escolar quanto aos que atuam em turmas de "atividades complementar", isto é, os "profissionais/monitores". Em um dos manuais de 2016 (BRASIL, 2016b, p. 50) são o "Profissional escolar em sala de aula responsável pelo desenvolvimento das atividades complementares"; noutro são o "Profissional ou monitor responsável pelo desenvolvimento das atividades complementares" (BRASIL, 2016c, p. 86), desaparecendo a sala de aula. Os subterfúgios criados para obrigar o professor à inserção voluntária na profissão, a abdicar de seus direitos trabalhistas, são imensos.

Ao procurarmos entender de que se tratam as "Atividades escolares", temos que são as

Atividades desenvolvidas na escola que objetivam o aprofundamento e/ou a complementação de conhecimentos previstos pelo currículo obrigatório. Nesse caso, as atividades escolares são aquelas desenvolvidas na escolarização e nas atividades complementares. (BRASIL, 2016b, p. 50).

Nas atividades complementares, atuam os voluntários para que a Educação Integral, via Mais Educação, se realize. Entre os "professores" que a realizam, 89\% são temporários, que 
podem ser designados de "paraprofessores"22. Os voluntários concentram-se prioritariamente nessa área de atuação.

\section{Elementos para a análise do contrato temporário}

Os dados exibidos figuram na cena trágica da educação brasileira. Longe de espelharem meramente "descaso" ou "abandono" do Estado em relação à educação pública, ostentam a bem delineada intencionalidade política que perpassa e ultrapassa, entre outros aspectos, as formas de contratação precária do magistério.

Os professores temporários formam uma massa de trabalhadores permanentemente colocados na escola, sujeita, certamente, a uma série quase infinita de fragilidades sociais, políticas e laborais. Se como categoria contratual, é imprescindível para o funcionamento da escola, tanto do ponto de vista dos interesses políticos quanto da vida escolar; como indivíduo está em constante ameaça de perda das condições de manutenção da vida.

O problema não é pequeno, haja vista o gigantismo do número de temporários. Soma-se a isso, a utilização de diversas nomenclaturas que vilipendiam a atividade propriamente docente. Entre elas, citamos monitor, tutor, mediador da aprendizagem, oficineiro, facilitador ${ }^{23}$. Além dessas, cada ente federado atribui uma denominação particular ao temporário. $\mathrm{Na}$ Bahia, por exemplo, chama-se PST (Prestação de Serviço Temporário); em Florianópolis, ACT (Admitidos em Caráter Temporário); em Alagoas, Monitor; no Paraná, PSS (Processo Seletivo Simplificado); no Rio Grande do Sul, Contratação Temporária. Em São Paulo, além do "eventual", há o OFA (Ocupantes de Função Atividade), correspondente ao ACT.

O que-fazer docente vem sendo sequestrado pelas políticas atuais que sobrelevam a aprendizagem em detrimento do ensino, dispensam disciplinas como História para priorizarem conteúdos socioemocionais, substituem professores com formação pelos de notório saber. Um dos casos mais chocantes e funestos concretiza-se no "eventual", modalidade paulista que nasce da precarização generalizada das condições de trabalho, no interior da qual floresce o absenteísmo docente.

Segundo Novaes (2010, p. 254), os eventuais não têm vínculo empregatício; seus vencimentos referem-se, somente, às aulas efetivamente ministradas; recebem pela hora-aula ministrada valor menor; não existem no estatuto do magistério; não são considerados no plano de carreira; só "descobrem" no momento da aula para qual turma irão e quais professores substituirão; eventuam, não lecionam; suprem ausências aleatoriamente; não planejam; vivem em

\footnotetext{
22 Para Shiroma e Evangelista (2015, p. 319, grifos nossos): “A expressão 'paraprofessores' designa os sujeitos que trabalham temporariamente na escola e que são apresentados pela International Development Association (IDA) do Banco Mundial (BM) como solução para a dramática falta de professores habilitados em muitos países. Não são profissionais, têm baixos níveis de formação e, embora não possuam habilitação para exercer a docência, atuam como professores (BWP, 2013). No Brasil, podem ser considerados paraprofessores aqueles admitidos sem processos públicos de seleção, que se multiplicaram em função dos programas assistencialistas, caso do 'Mais Educação', insuflados para manter alunos nas escolas - fora das ruas, portanto - executando atividades variadas, muitas vezes desvinculadas das propriamente pedagógicas".

23 A despeito da situação precária em que se encontram os temporários, o INEP criou dois novos indicadores: "adequação docente" e "esforço docente". Para o INEP (BRASIL, 2016c, p. 82), “[...] independentemente das condições do alunado, é possível ter bons desempenhos, apesar de os esforços para isso serem muito diferentes". Implementados a partir do Censo da Educação Básica de 2016, não se sabe ainda qual será sua utilização. Não duvidamos que venha servir de argumento para hierarquizar os professores entre mais e menos adequados, mais e menos esforçados. Renova-se o mito do professor salvacionista, da educação redentora, agora relida sob o signo da responsabilização docente. Esses indicadores abrem novas possibilidades de normas específicas de controle docente.
}

Práxis Educativa, Ponta Grossa, v. 12, n. 3, p. 942-959, set./dez. 2017 Disponível em: <http://www.revistas2.uepg.br/index.php/praxiseducativa $>$ 
situação de itinerância de acordo com as informações sobre professores faltosos em várias escolas; não estão vinculados a nenhuma unidade escolar; "eventuam" em mais de uma escola; não participam da vida escolar. O autor considera essa situação impiedosa, pois “[...] a manutenção do próprio trabalho depende da desagregação do trabalho pedagógico do próprio local de trabalho, em virtude do excessivo número de faltas dos docentes da unidade em que atuam" (NOVAES, 2010 , p. 262). O pesquisador sintetiza: eles "[...] convivem com a ambiguidade de serem úteis, sem serem importantes" (NOVAES, 2010, p. 262). Não é difícil entender porque os eventuais criaram a expressão "eventuar" e se refiram como "eventuais", exemplo indecoroso de um largo processo histórico de destruição da categoria do magistério ${ }^{24}$.

As políticas docentes propostas pelo Estado e por OMs, segundo interesses do capital, apresentam formas contratuais não efetivas, temporárias, revestidas de argumentos que obscurecem seu sentido essencial. O Estado, ao organizar dados relativos aos professores, utiliza nomenclaturas, como vimos, que elidem a função docente. As novas formas de contratação, como é o caso da Lei do Voluntariado (BRASIL, 1998), aparentemente, processaria uma política de valorização do trabalho pedagógico tendo em vista que as diversas possibilidades de ação escolar se encontrariam formalizadas, o que não ocorreu.

A permanência dos temporários é a evidência maior de seu caráter não acidental e não "temporário", mas de uma política que visa manter grande parte dos professores (41\% ou quase um milhão, em 2015, como demonstrado) sob o regime da instabilidade. Por outro lado, fica patente como os slogans procuram elidir a dinâmica de violência perene do capital em suas investidas na escola pública. Perpassa esse último aspecto aquilo que Mészáros (2015, p. 58) denomina "ilegalidade incorrigível do Estado", ou seja, o permanente descumprimento de suas próprias leis, o que "[...] reside em sua constituição mais íntima como árbitro soberano sobre a lei e, portanto, acima da lei" (MÉSZÁROS, 2015, p. 58). Funciona como um modo de controle, parte da ordem sociometabólica do sistema do capital.

É necessária e urgente a reflexão sobre a proeminência do tempo interrompido nas relações de trabalho, parte da precarização sofrida pelo magistério em geral, e a "intermitência" impeditiva da organização de sua vida pessoal. As análises sobre o trabalho docente no Brasil precisam ter em conta os impactos pedagógicos deletérios do fenômeno. Não é difícil imaginar as consequências para a ação pedagógica desse movimento oscilatório: rompimento de vínculos com a equipe da escola; dificuldade de contrair vínculos com os alunos; dificuldades de elaborar planejamentos ou mesmo de escolher os materiais didáticos com os quais irá trabalhar; dificuldades de inserção nas relações familiares e comunitárias inerentes à escola; impossibilidade de construir uma carreira na rede pública de ensino; entraves para seguir com a formação, especializações e pós-graduações, pois estão fora dos planos de carreiras ${ }^{25}$; limites no amadurecimento das próprias formas de intervenção pedagógica - a lista é inesgotável!

\footnotetext{
${ }^{24}$ Se a existência do eventual já expressa a desumanidade imposta aos professores, outro fato corrobora essa afirmação. Em Santa Catarina, uma Prefeitura Municipal lançou Edital, n. 018/2017, para contratar, na modalidade pregão com menor preço global, professores de Educação Física. Weiss (2017) assim se referiu: “Quem dá menos de $\mathrm{R} \$ 1,2$ mil para ensinar educação física em duas escolas por 20 horas semanais? Ou melhor, quem cobra menos? A prefeitura de Angelina, cidade de cinco mil habitantes da Grande Florianópolis, abriu licitação para 'contratação de serviços de instrutor de atividades físicas' por meio de lance de menor preço".

${ }^{25}$ Conquanto os temporários não sejam contemplados por planos de carreira, não se pode afirmar que os estáveis possam, na totalidade, usufruir, por exemplo, da licença para estudos. Em geral, apenas um pequeno percentual de professores tem podido continuar sua formação.
}

Práxis Educativa, Ponta Grossa, v. 12, n. 3, p. 942-959, set./dez. 2017 Disponível em: < http://www.revistas2.uepg.br/index.php/praxiseducativa> 
A vida em sobressaltos do professor temporário ${ }^{26}$ repercute também em sua atuação sindical em razão do fato de que se obstaculiza a construção de laços de solidariedade política em uma conjuntura de desemprego estrutural e de fortes ajustes da educação brasileira às necessidades do regime de acumulação do capital. Em Alagoas, por exemplo, o estado que concentra o maior percentual de temporários, 83\%, em 2015, denomina-se essa categoria de "monitores". As dificuldades colocadas na sindicalização desse grupo criaram impasses políticos que o levou à fundação de um sindicato em separado para lutar, ao menos, para que sejam considerados professores (GOMES, 2017) ${ }^{27}$. Contudo, essa dinâmica oscilatória - na qual os professores não sabem se trabalharão, em qual rede trabalharão no próximo período ou, ainda, se serão obrigados a combinar seu trabalho nas escolas públicas com outros - gera maior instabilidade na categoria, tornando-se terreno fecundo para o avanço de sua despolitização.

Não se pode perder de vista, ademais, que há um processo de produção em massa de certificação docente, na modalidade EaD e em IES particulares, que joga no mercado educacional professores com qualificação discutível, propensos à aceitação de qualquer forma de contrato trabalhista, componente orgânico da constituição do exército industrial de reserva que conduz à compressão dos salários. Isso resulta em uma individualização da percepção do problema, perdendo-se de vista suas determinações sociais e podendo conduzir os professores a não compreenderem que sua inserção precária nas relações de trabalho faz parte da lógica dominante. Tal situação não pode ser pretexto para fazer coro à ladainha da "responsabilização" individual dos professores, o esforço analítico precisa levar-nos a compreender as fronteiras da imoralidade da política posta pelo capital para a educação em nosso país: enorme contingente de professores vive permanentemente entre a cruz e a espada, entre um trabalho precário e o desemprego, ressalvadas as outras situações de precariedade que a eles se impõem.

A flexibilização das leis trabalhistas no Brasil e suas consequências sobre o mercado de trabalho podem ser vistas como uma das faces da precarização do trabalho, inserida na grita neoliberal, parte do movimento imperialista do capital, principalmente a partir da década de 1990. A mudança nas relações de produção capitalista corresponderia à forma predominante de organizar o trabalho, na qual "[...] preferem-se contratos de curto prazo a fim de maximizar a flexibilidade” (HARVEY, 2013, p. 181), fazendo crescer a acumulação capitalista.

O processo de expansão das relações capitalistas no mundo trouxe como elemento-chave a concorrência internacional, levando a que os trabalhadores competissem pela venda de sua força de trabalho, resultado da desregulamentação dos mercados e liberalização do deslocamento

${ }^{26}$ O grupo Todos pela Educação, organização que congrega interesses do capital nacional e internacional no Brasil, publicou, em parceria com a Fundação Santillana e apoio do Itaú BBA e do Instituto Península, trabalho coordenado por Abrucio (2016) sobre professores. Acerca dos temporários, o texto afirma que: "Um número bastante grande de professores tem contrato temporário por longo tempo. [...] Uma situação temporária que se prolonga e se torna 'definitiva' gera precarização do trabalho e afeta a motivação para a formação continuada” (ABRUCIO, 2016, p. 53). Essa posição aparentemente crítica cai por terra quando o autor defende a contratação temporária de egressos do Programa Institucional de Bolsa de Iniciação à Docência (Pibid) como uma das 15 estratégias para melhorar a formação docente. Sugere criar programas de estágios e residências pedagógicas em parceria com estados e municípios, aproveitando as lições do Pibid e acoplando o modelo de prática pedagógica à graduação com algum mecanismo de aproveitamento dos discentes na função docente. Esse pensamento expõe a proposta do capital em sua crueza em relação à formação de um novo tipo de professor: temporário, flexível e formado basicamente pela prática. De outro lado, assinala ser preciso compreender que o envelhecimento do corpo docente abre uma "janela de modificação formativa" do magistério, sendo um bom momento para sua substituição por um novo modelo, afeito às demandas do capital.

${ }^{27}$ Em 2015, o sindicato dos professores de Alagoas afirmava que “[...] questões de natureza jurídica impedem nossa entidade" de representar os temporários (SINTEAL, 2015). Assim, após quinze anos nesse impasse político, fundouse o Sindicato dos Professores Contratados da Rede Pública de Alagoas (Sinprocorpal). O SINTEAL (2016) mudou de posição e terminou por acusar o Sinprocorpal de divisionismo (SINPROCORPAL, 2017).

Práxis Educativa, Ponta Grossa, v. 12, n. 3, p. 942-959, set./dez. 2017 Disponível em: <http://www.revistas2.uepg.br/index.php/praxiseducativa> 
do capital em busca de menores custos de produção. Nesse contexto, restou mais evidente a demanda por flexibilização das relações de trabalho como forma de redução dos custos envolvidos, entre outros, nas contratações e nas demissões de trabalhadores, posto que o capital necessita de maior flexibilidade em relação às fronteiras internacionais, estaduais, municipais. Esse movimento foi oportunamente acompanhado pelas Organizações Multilaterais (OM), como a Organização das Nações Unidas para a Educação, a Ciência e a Cultura (UNESCO) e o Banco Mundial (BM), que articularam em suas proposições políticas diretrizes para o trabalho, negociadas com as burguesias dos Estados nacionais.

No campo educacional, a precarização, como conceito analítico, ganhou espaço na literatura principalmente a partir dos anos 2000 (MARIN, 2010). Desde então, a formulação "trabalho docente precarizado" disseminou-se na literatura crítica da área. Os trabalhadores da educação deveriam ter contratos de trabalho que permitissem maior mobilidade entre escolas e turmas, redução dos direitos e estabilidade laboral, salários pagos em função da demanda do mercado, da eficiência e da produtividade do trabalho, formação para múltiplas funções, entre outros.

Todos esses aspectos resultaram das investidas do capital contra o trabalho, articulados no campo das contradições postas no Estado. Na educação, tais proposições são articuladas por intelectuais coletivos como as OMs e organizações ditas privadas - cujo exemplo maior na história recente talvez seja o Todos pela Educação ${ }^{28}$ - com o propósito de casar, a um só termo, consenso e coerção a serviço do ajustamento da educação brasileira às íntimas demandas do padrão de acumulação, diga-se, em contexto de crise internacional do capital, cuja expressão tem se tornado mais concreta desde meados dos anos 2000.

\section{Conclusão preliminar}

Os dados sobre a contratação de professores temporários revelam uma das faces da precarização do trabalho docente no Brasil, aquela que mancha a temporalidade com uma tintura perversa. Vimos um retrato da brutalidade a qual está submetida grande parte do professorado. Os números, por si mesmos, não dizem tudo o que resta à garganta. Quase um milhão de professores no Brasil trabalham, a cada ano, sem ter a certeza da continuidade de suas atividades, privados da possibilidade de planejar em longo prazo suas relações didático-pedagógicas, alheados da escolha de recursos e materiais ou, mesmo, de planejamento. Sobretudo, são professores que precisam descobrir, a cada fim de contrato, como irão continuar ganhando a vida. São esses professores, responsáveis - e responsabilizados - pela educação de 48,8 milhões de crianças, jovens, adultos e idosos no Brasil (BRASIL, 2017c). A tragédia não é nova, episódica ou passageira, mas elemento característico da estrutura educacional brasileira. Fagocitose endêmica do acesso ao conhecimento em sentido verdadeiramente humano. $\mathrm{O}$ cinismo do Governo Federal não tem limites.

Devido ao elevado número de professores públicos no país, mais de dois milhões, o risco subjacente à unificação da carreira docente e das formas contratuais é o de uma erupção em grande escala. Os professores compõem a maior categoria de funcionários públicos do mundo (SHIROMA; EVANGELISTA, 2011, p. 129), razão pela qual o capital precisa neutralizá-los, amansá-los, docilizá-los ou, em último caso, quebrá-los em sua organização sindical ou, mesmo, destruí-los fisicamente.

\footnotetext{
28 Segundo informação de sua página: "Em fevereiro de 2014, o movimento teve seu estatuto reformado para se qualificar como Organização da Sociedade Civil de Interesse Público (Oscip)” (TPE, 2017).
} 
Nossa hipótese é a de que o trabalho temporário não pode ser solucionado, pois sua permanência faz parte da política de contenção de possíveis movimentos disruptivos dos professores. De outra parte, as condições precarizadas em que esse trabalho é desenvolvido dificultam, em muito, a construção da consciência crítica das novas gerações de estudantes e de novos desdobramentos históricos. Mais uma vez, a juventude está em causa, seja pela tentativa de cerceamento do pensamento e atuação do professor, seja do aluno, ao qual se nega as ferramentas para a reflexão sobre sua materialidade histórica. Em última instância, trata-se de tentar incapacitar a classe trabalhadora de reunir o instrumental necessário para a construção de sua consciência de classe, assim como para sua conversão em classe universal, nas palavras de Marx (2005).

\section{Referências}

ABRUCIO, F. L. (Coord.). Formação de professores no Brasil: diagnóstico, agenda de políticas e estratégias para a mudança. São Paulo: Moderna, 2016.

BID. Banco Interamericano de Desenvolvimento. Dimensiones del éxito en educación. 2014. Disponível em: <http://www.iadb.org/es/temas/educacion/educacion-en-america-latina-y-elcaribe,6448.html>. Acesso em: 24 jun. 2017.

BRASIL. Constituição (1988). Constituição da República Federativa do Brasil. Brasília, DF: Senado, 1988.

BRASIL. Lei No 9.394, de 20 de dezembro de 1996. Estabelece as diretrizes e bases da educação nacional. Diário Oficial [da] República Federativa do Brasil, Poder Legislativo, Brasília, DF, 23 dez. 1996. Seção 1, n. 248, p. 27833-27841.

BRASIL. Lei no 9.608, de 18 de fevereiro de 1998. Dispõe sobre o serviço voluntário e dá outras providências. Diário Oficial [da] República Federativa do Brasil, Poder Legislativo, Brasília, DF, 19 fev. 1998. Seção 1, n. 35, p. 2.

BRASIL. Ministério da Educação. FNDE. Resolução/CD/FNDE Nº 31, de 22 de julho de 2013. Dispõe sobre a destinação de recursos financeiros, nos moldes operacionais e regulamentares do Programa Dinheiro Direto na Escola (PDDE), às escolas públicas dos Estados e do Distrito Federal de ensino médio selecionadas pelas respectivas secretarias de educação que aderirem ao Programa Ensino Médio Inovador (ProEMI), com vistas a apoiar e fortalecer o desenvolvimento de propostas curriculares inovadoras nesse nível de ensino. Diário Oficial [da] República Federativa do Brasil, Poder Executivo, Brasília, DF, 23 jul. 2013a. Seção 1, n. 140, p. 15-16.

BRASIL. Ministério da Educação. FNDE. Resolução No 34, de 6 de setembro de 2013, Destina recursos financeiros, nos moldes operacionais e regulamentares do Programa Dinheiro Direto na Escola (PDDE), a escolas públicas municipais, estaduais e do Distrito Federal, para assegurar que essas realizem atividades de educação integral e funcionem nos finais de semana, em conformidade com o Programa Mais Educação. Diário Oficial [da] República Federativa do Brasil, Poder Executivo, Brasília, DF, 9 set. 2013b. Seção 1, n. 174, p. 28-30.

BRASIL. Lei No 13.005, de 25 de junho de 2014. Aprova o Plano Nacional de Educação - PNE e dá outras providências. Diário Oficial [da] República Federativa do Brasil, Poder Legislativo, Brasília, DF, 26 jun. 2014a. Seção 1, n. 120-A, edição extra, p. 1-7. 
BRASIL. Tribunal de Contas da União. Ensino médio no Brasil. Brasília: TCU, 2014b. Disponível em: < http://portal2.tcu.gov.br/portal/pls/portal/docs/2642558.PDF >. Acesso em: 9 dez. 2015.

BRASIL. Ministério da Educação. FNDE. Resolução no 4, de 25 de outubro de 2016. Destina recursos financeiros, nos moldes operacionais e regulamentares do Programa Dinheiro Direto na Escola - PDDE, a escolas públicas estaduais e do Distrito Federal, a fim de apoiar e fortalecer o desenvolvimento de propostas curriculares inovadoras, em conformidade com o Programa Ensino Médio Inovador. Diário Oficial [da] República Federativa do Brasil, Poder Executivo, Brasília, DF, 26 out. 2016a. Seção 1, n. 206, p. 12.

BRASIL. Ministério da Educação. INEP. Orientações de preenchimento do Censo Escolar 2016: Programas e Políticas Federais. Brasília, 2016b. Disponível em: <http://download.inep.gov.br/educacao_basica/educacenso/matricula_inicial/2016/document os/orientacoes_de_preenchimento_do_censo_escolar_2016_programas_e_politicas_federais.pdf >. Acesso em: 24 jun. 2017.

BRASIL. Ministério da Educação. INEP. Censo Escolar da Educação Básica 2016: Caderno de Instruções. Brasília, 2016c. Disponível em: $<$ http://download.inep.gov.br/educacao_basica/educacenso/matricula_inicial/2016/document os/caderno_de_instrucoes_2016.pdf $>$. Acesso em: 24 jun. 2017.

BRASIL. Ministério da Educação. Seja um professor. Brasília, 2017a. Disponível em: $<$ http://sejaumprofessor.mec.gov.br> Acesso em: 20 jun. 2017.

BRASIL. Onde trabalhar. Brasília, 2017b. Disponível em: $<$ http://sejaumprofessor.mec.gov.br/internas.php?area $=$ mercado\&id=ondeTrab. $>$. Acesso em: 20 jun. 2017.

BRASIL. Ministério da Educação. INEP. Censo Escolar da Educação Básica 2016: Notas Estatísticas. Brasília-DF, Fevereiro, 2017c. Disponível em: <http://download.inep.gov.br/educacao_basica/censo_escolar/notas_estatisticas/2017/notas_e statisticas_censo_escolar_da_educacao_basica_2016.pdf>. Acesso em: 24 jun. 2017.

CARVALHO, I. O fetiche do "Empoderamento": do conceito ideológico ao projeto econômicopolítico. In: MONTAÑO, C. (Org.). O canto da sereia: crítica à ideologia e aos projetos do Terceiro Setor. São Paulo: Cortez, 2014. p. 144-184.

CNTE. Confederação Nacional dos Trabalhadores em Educação. Confira o quadro de pagamento do piso nos municípios. 2017. Disponível em: <http://www.cnte.org.br/images/stories/2017/Piso_cumprimento_municipios.pdf>. Acesso em: 21 jun 2017.

CNTE. Confederação Nacional dos Trabalhadores em Educação. Saiba quais estados brasileiros não respeitam a Lei do Piso. 2016. Disponível em: <http://www.cnte.org.br/index.php/tabela-salarial.html>. Acesso em: 21 jun. 2017.

COAN, M. Educação para o empreendedorismo: implicações epistemológicas, políticas e práticas. 2011. 540 f. Tese (Doutorado em Educação) - Universidade Federal de Santa Catarina, Florianópolis, 2011. 
DECKER, A. I. A formação docente no projeto político do Banco Mundial (2000-2014). 2015. 234 f. Dissertação (Mestrado em Educação) - Universidade Federal de Santa Catarina, Florianópolis, 2015.

EVANGELISTA, O. Faces da tragédia docente do Brasil. In: MOTTA, V. C.; PEREIRA, L. Educação e serviço social: subsídios para análise crítica. Rio de Janeiro: Lumen Juris, 2017. p. 159-185.

G1. Inadimplência no ensino superior em 2015 é a maior dos últimos 5 anos. 2016. Disponível em: < http://g1.globo.com/educacao/noticia/inadimplencia-no-ensino-superior-em2015-e-a-maior-dos-ultimos-5-anos.ghtml>. Acesso em: 21 jun 2017.

GODOY, M. Vencimento, remuneração e carreira docente no estado do Paraná (20052012). 2014. 122 f. Dissertação (Mestrado em Educação) - Universidade Federal do Paraná, Curitiba, 2014.

GOMES, T. A. M. M. Contratação de professores temporários nas redes estaduais de ensino no Brasil: implicações para a categoria docente. 2017. 101 f. Dissertação (Mestrado em Educação) - Universidade Federal do Rio de Janeiro, Rio de Janeiro, 2017.

HARVEY, D. O neoliberalismo: história e implicações. 4. ed. São Paulo: Loyola. 2013.

JONGE, E.; WIJFFELS, J.; VAN DER LAAN, J. ffbase: Basic Statistical Functions for Package 'ff. R package version 0.12.3., 2016. Disponível em: <https://CRAN.Rproject.org/package=ffbase $>$. Acesso em: 24 jun. 2017.

MARIN, A. J. Precarização do trabalho docente. In: OLIVEIRA, D. A.; DUARTE, A. M. C.; VIEIRA, L. M. F. Dicionário: trabalho, profissão e condição docente. Belo Horizonte: UFMG/Faculdade de Educação, 2010. CDROM. Disponível em: <http://www.gestrado.net.br/pdf/331.pdf> Acesso em: 7 ago. 2017.

MARX, K. Crítica da filosofia do direito de Hegel. São Paulo: Boitempo, 2005.

MÉSZÁROS, I. A montanha que devemos conquistar. São Paulo: Boitempo Editorial, 2015.

MIRANDA, K. As transformações contemporâneas no trabalho docente: repercussões em sua natureza e seu processo de trabalho. In: SEMINÁRIO DA REDESTRADO - Regulação Educacional e Trabalho Docente, 6., 2006, Rio de Janeiro. Anais... Rio de Janeiro: UFRJ, 2006. p. 1-12. Disponível em: <http://www.fae.ufmg.br/estrado/cd_viseminario/trabalhos/eixo_tematico_1/as_transformac oes_comtemp.doc $>$ Acesso em: 7 ago. 2017.

NOVAES, L. C. A formação des(continuada) dos professores temporários: provisoriedade e qualidade de ensino. Revista Diálogo Educacional, Curitiba, v. 10, n. 30, p. 247-265, maio/ago. 2010.

OBPNE. Observatório do PNE. Disponível em: <http://www.observatoriodopne.org.br>. Acesso em: 24 jun. 2017. 
PRADO, L. R. Juventude em crise. Brasil de Fato. 2012. Disponível em: <https://www.brasildefato.com.br/node/11289>. Acesso em: 24 jun. 2017.

R CORE TEAM. R: A language and environment for statistical computing. R Foundation for Statistical Computing, Vienna, Austria, 2016. Disponível em: <http://www.R-project.org>. Acesso em: 23 fev. 2017.

SHIROMA, E. O.; EVANGELISTA, O. Avaliação e responsabilização pelos resultados: atualizações nas formas de gestão de professores. Perspectiva, Florianópolis, v. 29, n. 1, p. $127-$ 160, jan./jun. 2011. DOI: 10.5007/2175-795x.2011v29n1p127

SHIROMA, E. O.; EVANGELISTA, O. Formação humana ou produção de resultados? Trabalho docente na encruzilhada. Revista Contemporânea de Educação, Rio de Janeiro, v. 20, n. 10, p. 314-341, dez. 2015. DOI: 10.20500/rce.v10i20.2730

SINPROCORPAL. Monitores da educação devem fundar sindicato para representar a categoria em Alagoas. 2017.2 Disponível em: $<$ http://sinprocorpal.com.br/2017/04/02/monitores-da-educacao-devem-fundar-sindicatopara-representar-a-categoria-em-al>. Acesso em: 21 jun. 2017.

SINTEAL. Nota Pública do Sindicato dos Trabalhadores em Educação de Alagoas. 2016. Disponível em: <http://www.sinteal.org.br/2016/08/nota-publica-do-sinteal-2>. Acesso em: 24 jun. 2017.

SINTEAL. Sindicato dos Trabalhadores em Educação de Alagoas se reúne com movimento de monitores. 2015. Disponível em: <http://www.sinteal.org.br/2015/08/sintealse-reune-com-movimento-de-monitores>. Acesso em: 21 jun. 2017.

STF. Supremo Tribunal Federal. Lei mineira que efetivou professores sem concurso é inconstitucional. Brasília, 2014. Disponível em: $<$ http://www.stf.jus.br/portal/cms/verNoticiaDetalhe.asp?idConteudo=263423>. Acesso em: 26 jun. 2017.

TOKARNIA, M. Revisão do Programa Mais Educação é uma das prioridades, diz MEC. UOL. Disponível em: <https://educacao.uol.com.br/noticias/2015/10/07/revisao-doprograma-mais-educacao-e-uma-das-prioridades-diz-mec.htm>. Acesso em: 24 jun. 2017.

TPE. O Todos Pela Educação. 2017. Disponível em: <https://www.todospelaeducacao.org.br/quem-somos/o-tpe>. Acesso em: 21 jun. 2017.

WEISS, C. E. Prefeitura de Angelina abre leilão para contratar professor de educação física por menor preço. Diário Catarinense, 2017. Disponível em: <https://goo.gl/TuyoE9>. Acesso em: 24 jun. 2017.

WORLD BANK. SABER - Systems Approach for Better Education Results. What matters most in teacher policies? A framework for building a more effective teaching profession, jun., 2012. Disponível em: <https://goo.gl/9KFr4x>. Acesso em: 12 jun. 2015.

WORLD BANK. SABER - Systems Approach for Better Education Results. What matters most for engaging the private sector in Education: A framework paper. Working Paper 
Allan Kenji Seki, Artur Gomes de Souza, Filipe Anselmo Gomes e Olinda Evangelista

Series, n. 8, Jul., 2014. Disponível em:

$<$ http://wbgfiles.worldbank.org/documents/hdn/ed/saber/supporting_doc/Background/EPS /SABER_Engaging_the_Private_Sector_in_Education_What_Matters_Framework_Paper.pdf $>$ Acesso em: 26 mar. 2017.

Recebido em 10/07/2017

Aceito em 22/08/2017

Publicado online em 28/08/2017 